\title{
Conjunction and disjunction in a language without 'and' *
}

\author{
Margit Bowler \\ $U C L A$
}

\begin{abstract}
Warlpiri (Pama-Nyungan, Australia) has a single coordinator, manu. This coordinator occurs in constructions of the form $P$ manu $Q$. In the following paper, I argue that manu has a non-strengthened disjunctive denotation $(V)$ which can undergo pragmatic strengthening to conjunction $(\&)$. I propose that the absence of a conjunctive coordinator in Warlpiri results in the set of scalar alternatives $\{\mathrm{P}$, $\mathrm{Q},(\mathrm{P} \vee \mathrm{Q})\}$ for $P$ manu $Q$. This is identical to the set of scalar alternatives for English $P$ or $Q$ proposed by Singh, Wexler, Astle, Kamawar, \& Fox (2013) for English-speaking children. I follow Singh et al. in using a recursive application of Fox's (2007) exhaustivity operator, Exh, to derive a strengthened conjunctive reading of $P$ manu $Q$ that is categorical in unembedded contexts. I also address strengthening under the scope of negation and in conditionals and Wh-questions, and place some pragmatic constraints on Exh application.
\end{abstract}

Keywords: Australian Aboriginal languages, conjunction, disjunction, exhaustification

\section{Introduction and overview of the Warlpiri data}

This paper addresses conjunction and disjunction in Warlpiri, a Pama-Nyungan language spoken by approximately 3,000 people in central Australia. Warlpiri has a single coordinator, manu, which occurs in constructions of the form $P$ manu $Q$. Manu can coordinate items of all lexical categories, including full clauses. Warlpiri speakers produce $P$ manu $Q$ in response to the unembedded English prompt ' $\mathrm{P}$ and Q,' and also translate unembedded $P$ manu $Q$ into English as 'P and Q.' ${ }^{1}$

In this paper, I will argue that manu has an unstrengthened denotation of inclusive 'or.' I propose that manu undergoes categorical pragmatic strengthening to conjunction in unembedded environments, and optional pragmatic strengthening in some

* I would like to thank my adviser Yael Sharvit for her insightful advice and encouragement. I would also like to thank Jessica Rett, Tim Stowell, and Roni Katzir for their helpful comments. In Australia, I would like to thank Cecilia Alfonso, Gloria Morales, and Rachel O'Connell. Finally, my deepest thanks go to my Warlpiri consultants Nancy Napurrurla Oldfield, Alma Nungarrayi Granites, Otto Jungarrayi Sims, Erica Napurrurla Ross, and Tess Napaljarri Ross. All remaining errors are my own. 1 I use the term "embedded context" to refer to anything embedded under the scope of a negative operator, Wh-operator, and so on.

(C2014 Bowler 
embedded environments such as in the antecedents of conditionals, Wh-questions, and so on. I will begin by providing an overview of the relevant Warlpiri data, and then move on to a discussion of the formal strengthening process.

\subsection{P manu $Q$ in unembedded contexts}

Manu is categorically interpreted as conjunction in unembedded contexts. Speakers are comfortable following unembedded $P$ manu $Q$ utterances with jirrama=juku 'two=exactly,' showing that unembedded $P$ manu $Q$ is compatible with a conjunctive reading:

Cecilia manu Gloria=pala yanu tawunu-kurra. Jirrama=juku.

Cecilia manu Gloria=3DU.SUBJ go.PST town-ALL two=exactly

'Cecilia and Gloria went to town. Exactly two did.' $2,3,4$

Jangala-rlu manu Jungarrayi-rli=pala luwarnu marlu.

Jangala-ERG manu Jungarrayi-ERG=3DU.SUBJ shoot.PST kangaroo

Jirrama=juku-rlu.

two=exactly-ERG

'Jangala and Jungarrayi shot the kangaroo. Exactly two did.'

(3) Ngapa ka wantimi manu warlpa ka wangkami.

water AUX fall.NPST manu wind AUX speak.NPST

'Rain is falling and wind is blowing.'

Furthermore, Warlpiri speakers are uncomfortable using unembedded $P$ manu $Q$ utterances in contexts in which they consider it possible that only one of $\{P, Q\}$ is true. This suggests that unembedded manu cannot be interpreted disjunctively.

To express disjunction, Warlpiri speakers use the periphrastic construction $P$ marda, Q marda 'maybe P, maybe Q:'

(4) Gloria marda, Cecilia marda yanu tawunu-kurra=ju.

Gloria maybe Cecilia maybe go.PST town-ALL=TOP

'Gloria or Cecilia went to town.'

(lit. 'Maybe Gloria, maybe Cecilia went to town.')

2 Abbreviations used in this paper include 1 'first person,' 2 'second person,' 3 'third person,' ALL 'allative,' AUX ‘auxiliary,' DAT 'dative,' DIREC ‘directional,' DU 'dual,' ELAT 'elative,' ERG 'ergative,' EXCL 'exclusive,' FUT 'future,' INCL 'inclusive,' IRR 'irrealis,' LOC 'locative,' NEG 'negation,' NPST 'nonpast,' NSUBJ 'nonsubject,' PL 'plural,' PST 'past,' SG 'singular,' and SUBJ 'subject.'

3 I gloss manu simply as 'manu' in this paper, since (as I will show) it has more than one interpretation. 4 I assume, solely for the purposes of presentation, that all instances of apparent non-Boolean coordination have underlying ellipsis. This has no bearing on my theoretical discussion. 
Conjunction and disjunction in a language without 'and'

I analyze $P$ marda, $Q$ marda constructions as conjunctions of epistemic possibilities involving a covert manu coordinator $(\diamond \mathrm{P} \& \diamond \mathrm{Q})$. These constructions are not interpreted as logical disjunctive statements (cf. Zimmermann's (2001) proposed communicative effects of disjunction), but rather simply as conjunctions of epistemic possibilities. However, in the interest of conserving space, I will not discuss this construction further.

\subsection{P manu $Q$ in embedded contexts}

In the following subsections, I present some data on $P$ manu $Q$ in embedded contexts.

\subsubsection{P manu $Q$ under the scope of negation}

Sentential negation is expressed in Warlpiri using a negative morpheme, kula, that combines with and precedes the second-position auxiliary. This kula-auxiliary complex can then optionally occur clause-initially:

$$
\begin{aligned}
& \text { Kula=rna yanu tawunu-kurra. } \\
& \text { NEG=1 SG.SUBJ go.PST town-ALL } \\
& \text { 'I didn't go to town.' }
\end{aligned}
$$

In constructions involving sentential negation, Warlpiri speakers categorically interpret $P$ manu $Q$ as disjunction. Speakers are comfortable following $P$ manu $Q$ utterances under negation with lawa 'no'/'nothing,' showing that these expressions are compatible with the reading $(\neg \mathrm{P} \& \neg \mathrm{Q})$ :

(6) Cecilia manu Gloria kula=pala yanu Lajamanu-kurra. Lawa. Cecilia manu Gloria NEG=3DU.SUBJ go.PST Lajamanu-ALL nothing 'Neither Cecilia nor Gloria went to Lajamanu. Neither one.'

$$
\begin{aligned}
& \text { Kula=rna yunparnu manu wurntija jalangu. Lawa. } \\
& \text { NEG=1SG.SUBJ sing.PST manu dance.PST today nothing } \\
& \text { 'I didn't sing or dance today. I did nothing.' }
\end{aligned}
$$

Futhermore, speakers are uncomfortable using $P$ manu $Q$ under negation in contexts in which they consider it possible that only one of $\{\mathrm{P}, \mathrm{Q}\}$ is false. This also suggests that $P$ manu $Q$ under negation is interpreted disjunctively.

\subsubsection{P manu $Q$ in the antecedents of conditionals}

Warlpiri conditionals are formed using the irrealis morpheme kaji 'IRR.' Kaji has a similar distribution as kula 'NEG;' this morpheme combines with and precedes 
the second-position auxiliary. This kaji-auxiliary complex can then optionally occur clause-initially:

$$
\begin{aligned}
& \text { Kaji=npa yani japi-kirra, kuyu=ju manta. } \\
& \text { IRR=2SG.SUBJ go.NPST shop-ALL meat=TOP get.IMPER }
\end{aligned}
$$

'If you go to the shop, get some meat.'

The interpretation of $P$ manu $Q$ is ambiguous in this context. In this environment, $P$ manu $Q$ can be interpreted both conjunctively, as in (9), and disjunctively, as in (10):

(9) Kaji=npa kuyu manu mangarri ngarni ngula kapu=npa $I R R=2 S G . S U B J$ meat manu food eat.NPST that AUX.FUT=2SG.SUBJ pirrjirdi-jarrimi. strong-become.NPST 'If you eat meat and vegetables, you will become strong.' (Consultant's English translation of the Warlpiri utterance)

(10) Kaji=npa jarntu pakarni manu window luwarni, ngula=ju IRR=2SG.SUBJ dog hit.NPST manu window shoot.NPST that=TOP Nungarrayi-rli kapi=ngki jirna-wangu-mani.

Nungarrayi-ERG AUX.FUT=2SG.NSUBJ scold.NPST

'If you hit the dog or break the window, then Nungarrayi will scold you.' (Consultant's English translation of the Warlpiri utterance)

\subsubsection{P manu $Q$ in Wh-questions}

Warlpiri Wh-words typically undergo leftward Wh-movement to a clause-initial position and are accompanied by rising clause-final question intonation:

(11) Ngana-ngku ka mardarni ngaya?

who-ERG AUX have.NPST cat

'Who has a cat?'

Like in the antecedents of conditionals, the interpretation of $P$ manu $Q$ is also ambiguous in Wh-questions. $P$ manu $Q$ can be interpreted conjunctively, as in (12), and disjunctively, as in (13):

(12) Ngana-ngku ka mardarni ngaya manu jarntu?

who-ERG AUX have.NPST cat manu dog

'Who has a cat and a dog?'

(Consultant's English translation of the Warlpiri utterance) 
Conjunction and disjunction in a language without 'and'

\begin{tabular}{l|c}
\hline Context & $\boldsymbol{P}$ manu $\boldsymbol{Q}$ \\
\hline Unembedded environments & only conjunction \\
Under the scope of negation & only disjunction \\
Antecedents of conditionals & ambiguous \\
Wh-questions & ambiguous
\end{tabular}

Table 1 Distribution and interpretation of $P$ manu $Q$.

(13) Ngana yanu Juka Juka-kurra manu Wakulpa-kurra?

who go.PST Juka Juka-ALL manu Wakulpa-ALL

'Who has been to Juka Juka or Wakulpa?'

(Consultant's English translation of the Warlpiri utterance)

\section{Descriptive summary and lexical toolkit}

Warlpiri speakers express conjunction in unembedded contexts using $P$ manu $Q$. In negated constructions, $P$ manu $Q$ expresses disjunction. Furthermore, $P$ manu $Q$ is ambiguous between conjunction and disjunction in the antecedents of conditionals and in Wh-questions. The interpretation of $P$ manu $Q$ across these contexts is summarized in Table 1.

To account for the data in Table 1, I propose that Warlpiri speakers have the following lexical toolkit to express conjunction and disjunction:

$$
\begin{aligned}
& \llbracket \mathrm{manu} \rrbracket^{w}=\llbracket \mathrm{or}_{\text {English }} \rrbracket^{w}=\lambda \mathrm{t}_{1} \in \mathrm{D}_{t} . \lambda \mathrm{t}_{2} \in \mathrm{D}_{t} . \mathrm{t}_{1}=1 \vee \mathrm{t}_{2}=1 \\
& \llbracket \mathrm{marda}^{w}=\llbracket \text { maybe }_{\text {English }} \rrbracket^{w}=\lambda \mathrm{q} \in \mathrm{D}_{<s, t>} . \exists \mathrm{w}^{\prime} \in \text { Epistemic }_{w}: \mathrm{q}\left(\mathrm{w}^{\prime}\right)=1 \\
& \text { Warlpiri has no coordinator equivalent to } \llbracket \operatorname{and}_{\text {English }} \rrbracket^{w} .
\end{aligned}
$$

That is, Warlpiri manu has the same unstrengthened inclusive 'or' denotation as English or. Warlpiri marda (used in periphrastic $P$ marda, $Q$ marda 'maybe $\mathrm{P}$, maybe Q' constructions) has the same denotation as the English epistemic possibility modal maybe. Finally, there is no Warlpiri coordinator with a conjunctive denotation equivalent to English and.

\section{Strengthening $P$ manu $Q(P \vee Q)$ to conjunction $(P \& Q)$}

In the following subsection, I will outline my theoretical analysis of conjunction and disjunction in Warlpiri. I will begin by discussing the strengthening mechanism used to obtain the conjunctive reading of $P$ manu $Q$ from its unstrengthened disjunctive denotation of inclusive 'or.' This proposal follows Singh et al. (2013) and Meyer (2012), and utilizes the exhaustivity operator proposed by Fox (2007). 


\subsection{Scalar alternatives to $P$ manu $Q$}

Under a theory of scalar implicature, speakers uttering a statement $\mathrm{P}$ including a scalar item choose not to utter any stronger alternative statements, e.g., $\mathrm{P}^{\prime}, \mathrm{P}^{\prime \prime}$, which compete with $\mathrm{P}$ through the inclusion of these stronger alternative scalar items. This follows from the Gricean maxim of quantity, which states that (cooperative) speakers will be as informative as possible, but not more informative than is required (Grice 1975). In the context of disjunction, a listener hearing the utterance $P$ or $Q$ can infer that the speaker believes that the stronger scalar alternative $P$ and $Q$ is false.

I proposed in section 2 that the Warlpiri coordinator тапu has an unstrengthened disjunctive denotation. Furthermore, my overarching claim is that Warlpiri entirely lacks a coordinator with a conjunctive denotation. Since Warlpiri does not have a conjunctive coordinator, $(\mathrm{P} \& \mathrm{Q})$ is absent from the set of scalar alternatives to $P$ manu $Q$. When $(\mathrm{P} \& \mathrm{Q})$ is removed from this set of alternatives, the remaining set of scalar alternatives to $P$ manu $Q$ is simply $\{\mathrm{P}, \mathrm{Q},(\mathrm{P} \vee \mathrm{Q})\} .^{5}$

(17) and (18) below compare the set of scalar alternatives for Warlpiri $P$ manu $Q$ to the scalar alternatives for English $P$ or $Q$ :

Alternatives for $P$ or $Q$ :

$\{\mathrm{P}, \mathrm{Q},(\mathrm{P} \vee \mathrm{Q}),(\mathrm{P} \& \mathrm{Q})\}$

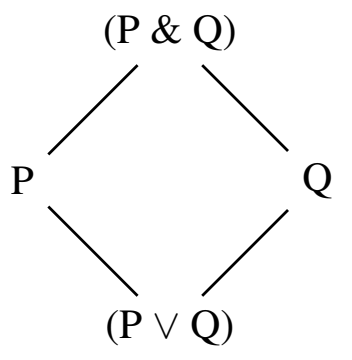

Alternatives for $P$ manu $Q$ : $\{\mathrm{P}, \mathrm{Q},(\mathrm{P} \vee \mathrm{Q})\}$

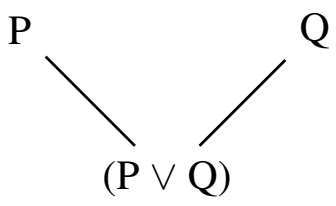

Since the alternatives for inclusive 'or' that are available to Warlpiri speakers are different from the alternatives that are available to English speakers, I predict that strengthening of inclusive 'or' will also proceed differently in Warlpiri. I describe this strengthening process in the following subsection.

\subsection{Strengthening mechanism}

The set of Warlpiri scalar alternatives presented in (18) is identical to the set of alternatives presented by Singh et al. (2013: 32) for the scale of disjunction used by English-speaking children. Singh et al. assert that this limited set of alternatives

5 I follow other authors (e.g. Sauerland (2004)) in assuming that the scale of disjunction includes the individual disjuncts $\{\mathrm{P}, \mathrm{Q}\}$ themselves. 
Conjunction and disjunction in a language without 'and'

$\{\mathrm{P}, \mathrm{Q},(\mathrm{P} \vee \mathrm{Q})\}$ results from the inability of English-speaking children to access the lexicon and include the scalar competitor $(\mathrm{P} \& \mathrm{Q})$ when generating alternatives to $P$ or $Q$. On the contrary, I propose that the set of alternatives available to Warlpiri speakers simply falls out from the lexical items that are available to them, rather than from any inability to access the lexicon. Since Warlpiri has only a single coordinator, тапи ( $\mathrm{P} \vee \mathrm{Q})$, speakers do not include any other alternative when they access the lexicon. Therefore, although the mechanisms of the following strengthening process are the same in both my proposal and in Singh et al.'s, our respective motivations for the set of alternatives to $(\mathrm{P} \vee \mathrm{Q})$ are not.

Additionally, strengthening to conjunction is observed only a portion of the time in Singh et al.'s results. They propose this suggests that children vary in accessing the lexicon. That is, in any sample of children, some will have already matured into the adult grammar and can perform lexical substitution when calculating alternatives (2013: 38). On the other hand, I propose that Warlpiri entirely lacks a conjunctive coordinator and speakers are never able to include a conjunctive alternative. In accordance with this proposal, strengthening $P$ manu $Q$ to conjunction is categorical in unembedded contexts in Warlpiri.

To account for this strengthening of disjunction to conjunction in childrens' English, Singh et al. adopt the exhaustivity operator Exh proposed by Fox (2007). I follow Singh et al. in utilizing a recursive application of Exh to account for the strengthening of $P$ manu $Q$ in Warlpiri. I additionally extend Singh et al.'s (2013) analysis to constructions that they do not consider in their paper. This includes the strengthening of $P$ manu $Q$ in the antecedents of conditionals and Wh-questions. I also accomplish this through the use of Fox's exhaustivity operator.

Exhaustification and Exh (Fox 2007) Fox 2007 is a syntactic account of the neo-Gricean approach to scalar implicatures. Fox's exhaustivity operator, Exh, is optionally present in the syntax. Since Exh is a syntactic operator, it can apply recursively to its own output; Fox (2007) uses recursive Exh application to account for the interpretation of English or under deontic possibility modality (e.g., You may have cake or ice cream). As I will show, potentially different sets of alternatives can be generated with each instance of Exh application. Furthermore, since Exh is located within the syntax, it can be used to generate "local" implicatures by attaching to embedded clauses.

Exh takes two arguments: a prejacent and the alternatives to that prejacent. Exh operates on a set of what I will call "innocently excludable" (IE) alternatives, which are derived from a set of "excludable" alternatives that can be excluded (negated) without contradicting the prejacent:

$$
\operatorname{EXCL}(\operatorname{ALT})(P)=\{\mathrm{S} \subseteq \mathrm{ALT}: \mathrm{S} \neq \varnothing \text {, and }\{\neg \mathrm{Q}: \mathrm{Q} \in \mathrm{S}\} \cup\{\mathrm{P}\} \text { is consistent }\}
$$


The set of IE propositions is calculated by taking the intersection of the maximal sets of these excludable propositions. Following Fox's proposal, the IE propositions are negated and combined with the prejacent to calculate the pragmatically strengthened meaning of the assertion:

$$
\operatorname{Exh}(\mathrm{ALT})(\mathrm{P})=(\mathrm{P} \& \text { for all innocently excludable (IE) Q in ALT: } \neg \mathrm{Q})^{6}
$$

When Exh is applied to adult English $P$ or $Q$, the result is exclusive disjunction $((\mathrm{P} \vee \mathrm{Q}) \& \neg(\mathrm{P} \& \mathrm{Q}))$. In the following subsection, I will derive the recursive application of Fox's Exh to the Warlpiri construction $P$ manu $Q$, yielding a conjunctive reading $(((\mathrm{P} \vee \mathrm{Q}) \& \neg(\neg \mathrm{P} \& \mathrm{Q}) \& \neg(\mathrm{P} \& \neg \mathrm{Q}))=(\mathrm{P} \& \mathrm{Q}))$. The use of $E x h$ enables me to derive the propositions $\{(\neg \mathrm{P} \& \mathrm{Q}),(\mathrm{P} \& \neg \overline{\mathrm{Q}})\}$ as negatable alternatives to $P$ manu $Q$. These propositions are absent from the set of alternatives to $P$ manu $Q$, as given in (18). However, as I will show, recursive Exh application makes them available.

\subsubsection{Application of Fox's (2007) exhaustivity operator to Warlpiri $P$ manu $Q$ $(\mathbf{P} \vee \mathbf{Q})$}

To reiterate, unlike $(\mathrm{P} \vee \mathrm{Q})_{\text {English }}$, the alternatives for Warlpiri $P$ manu $Q((\mathrm{P} \vee$ $\left.\mathrm{Q})_{\text {Warlpiri }}\right)$ are simply $\{\mathrm{P}, \mathrm{Q},(\mathrm{P} \vee \mathrm{Q})\}$. This is due to the lack of any other competing Warlpiri coordinator. That is:

$$
\operatorname{ALT}(\mathrm{P} \vee \mathrm{Q})_{\text {Warl piri }}=\{\mathrm{P}, \mathrm{Q},(\mathrm{P} \vee \mathrm{Q})\}
$$

Like the alternatives for $(\mathrm{P} \vee \mathrm{Q})_{\text {English }}$, these alternatives are constructed following Katzir (2008) and Fox \& Katzir (2011). That is, the node $P$ manu $Q$ is replaced by the type-relevant nodes it dominates (namely, $P, Q$ ). Unlike when constructing the alternatives of English $P$ or $Q$, however, Warlpiri speakers cannot perform lexical substitution for manu. This is because there are no lexical alternatives for manu.

When a Warlpiri listener parses the utterance $P$ manu $Q$ without applying Exh, they are left with the ignorance inferences that the speaker is not sure that $\mathrm{P}$, and the speaker is not sure that Q. To obtain a parse with fewer ignorance inferences, the listener applies Exh. This results in the following syntactic structure, where Exh combines with the set of alternatives (ALT) and the prejacent (P manu $Q)$ :

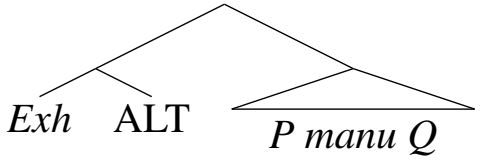

6 More accurately:

(i) $\llbracket \mathrm{Exh} \rrbracket^{w}(\mathrm{ALT})(\mathrm{P})=1$ iff $\mathrm{P}(\mathrm{w})=1$ and for all innocently excludable $\mathrm{Q}$ in ALT: $\mathrm{Q}(\mathrm{w})=0$. 
Conjunction and disjunction in a language without 'and'

When applying Exh, the listener attempts to negate as many of the alternatives as possible without contradicting the prejacent. Application of Exh to (ALT)(P $\vee$ Q) Warlpiri therefore yields the set of sets of excludable propositions in (23). The maximal members of this set, given in (24), are the same, since both sets in EXCL are singleton sets:

$$
\begin{aligned}
& \mathrm{EXCL}=\{\{P\},\{\mathrm{Q}\}\} \\
& \mathrm{EXCL}_{\text {max }}=\{\{\mathrm{P}\},\{\mathrm{Q}\}\}
\end{aligned}
$$

The intersection of the sets of excludable propositions in (24) is empty, which means that there are no IE propositions to negate and combine with the assertion:

$$
\begin{aligned}
& \mathrm{IE}=\cap \mathrm{EXCL}_{\max }=\varnothing \\
& \operatorname{Exh}(\mathrm{ALT})(\mathrm{P} \vee \mathrm{Q})=\underline{\mathrm{P} \vee \mathrm{Q}}
\end{aligned}
$$

Since no propositions can be excluded at this point in the derivation, the listener cannot make any progress with respect to removing ignorance inferences. However, since Exh is an operator that is present in the syntactic structure, it can be applied recursively to its own output (Fox 2007). In this case, application of Exh is motivated by the removal of ignorance inferences. The Warlpiri listener reapplies Exh in an attempt to remove as many ignorance inferences as possible. A recursive application of Exh results in the following structure:

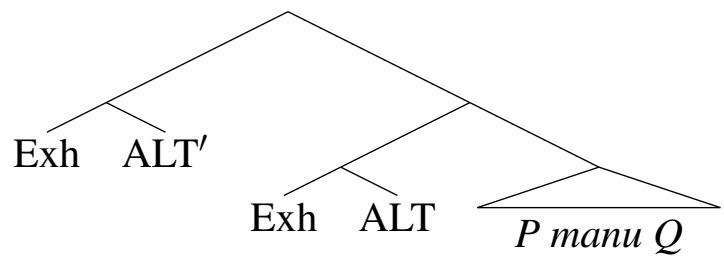

This occurrence of Exh first combines with the set of alternatives $\mathrm{ALT}^{\prime}$; the prejacent is the output of the previous derivation, or $\operatorname{Exh}(\mathrm{ALT})(\mathrm{P} \vee \mathrm{Q})$, as shown in (25). The alternatives contained in $\mathrm{ALT}^{\prime}$ and ALT are as follows: ${ }^{7}$

$$
\begin{aligned}
& \mathrm{ALT}^{\prime}=\{\operatorname{Exh}(\mathrm{ALT})(\mathrm{P}), \operatorname{Exh}(\mathrm{ALT})(\mathrm{Q}), \operatorname{Exh}(\mathrm{ALT})(\mathrm{P} \vee \mathrm{Q})\} \\
& \mathrm{ALT}=\{\mathrm{P}, \mathrm{Q},(\mathrm{P} \vee \mathrm{Q})\}
\end{aligned}
$$

I will proceed by calculating the value of each member of $\mathrm{ALT}^{\prime}$, beginning with $\operatorname{Exh}(\mathrm{ALT})(\mathrm{P})$, then $\operatorname{Exh}(\mathrm{ALT})(\mathrm{Q})$, and so on. Once this is complete, I will evaluate

7 Deriving ALT $^{\prime}$ based on Katzir's (2008) algorithm involves a complex calculation which I will not fully go into here. In short, Fox \& Katzir (2011) propose that the alternatives are derived via focus-marking. This effectively allows the generation of a tree where $P$ manu $Q$ is focus-marked, so no non-exhaustified alternatives (e.g., $P, Q$ ) are generated. See also Meyer 2012 regarding this issue. 
the expression $\operatorname{Exh}\left(\mathrm{ALT}^{\prime}\right)(\mathrm{P} \vee \mathrm{Q})$ to arrive at the final recursively strengthened meaning of $P$ manu $Q$.

Negatable subsets of ALT relative to the prejacent $(P)$ are only $\{Q\}$. Since this is a singleton set, EXCL $\mathrm{Eax}_{\text {max }}$ is the same. Parallel results obtain when calculating negatable subsets of ALT relative to the prejacent (Q). The strengthened interpretations of these prejacents are (P \& $\neg \mathrm{Q})$ and (Q \& $\neg \mathrm{P})$, as shown in (29) and (30) below:

$$
\begin{aligned}
& \operatorname{EXCL}(\operatorname{ALT})(P)=\{\{\mathrm{Q}\}\} \\
& \mathrm{IE}=\cap \mathrm{EXCL}_{\max }=\{\mathrm{Q}\} \\
& \operatorname{Exh}(\mathrm{ALT})(\mathrm{P})=(\mathrm{P} \& \neg \mathrm{Q}) \\
& \mathrm{EXCL}(\mathrm{ALT})(\mathrm{Q})=\{\{\mathrm{P}\}\} \\
& \mathrm{IE}=\cap \operatorname{EXCL} \text { max }=\{\mathrm{P}\} \\
& \operatorname{Exh}(\mathrm{ALT})(\mathrm{Q})=(\mathrm{Q} \& \neg \mathrm{P})
\end{aligned}
$$

As shown previously in (23)-(25), application of Exh to (ALT)(P $\vee \mathrm{Q}$ ) simply yields $(\mathrm{P} \vee \mathrm{Q})$ as the result, with no IE propositions being excluded:

$$
\begin{aligned}
& \operatorname{EXCL}(\mathrm{ALT})(\mathrm{P} \vee \mathrm{Q})=\{\{\mathrm{P}\},\{\mathrm{Q}\}\} \\
& \mathrm{EXCL}_{\max }=\{\{\mathrm{P}\},\{\mathrm{Q}\}\} \\
& \mathrm{IE}=\cap \mathrm{EXCL}_{\max }=\varnothing \\
& \operatorname{Exh}(\mathrm{ALT})(\mathrm{P} \vee \mathrm{Q})=(\mathrm{P} \vee \mathrm{Q})
\end{aligned}
$$

In (27), I gave the set of elements within $\mathrm{ALT}^{\prime}$ in terms of Exh. After calculating the propositional value of each expression in (29)-(31), this results in the following propositions within $\mathrm{ALT}^{\prime}$ :

$$
\mathrm{ALT}^{\prime}=\{(\mathrm{P} \& \neg \mathrm{Q}),(\mathrm{Q} \& \neg \mathrm{P}),(\mathrm{P} \vee \mathrm{Q})\}
$$

I can now evaluate the expression $\operatorname{Exh}\left(\mathrm{ALT}^{\prime}\right)(\operatorname{Exh}(\mathrm{ALT})(\mathrm{P} \vee \mathrm{Q}))$ by calculating the subsets of $\mathrm{ALT}^{\prime}$ in (32) that can be negated without contradicting the prejacent, $\operatorname{Exh}(\mathrm{ALT})(\mathrm{P} \vee \mathrm{Q})$. I will refer to these excludable and innocently excludable propositions as $\mathrm{EXCL}^{\prime}$ and $\mathrm{IE}^{\prime}$, respectively. Recall from (25) that $\operatorname{Exh}(\mathrm{ALT})(\mathrm{P} \vee \mathrm{Q})=(\mathrm{P}$ $\vee \mathrm{Q})$ :

$$
\begin{aligned}
& \mathrm{EXCL}^{\prime}\left(\mathrm{ALT}^{\prime}\right)(\operatorname{Exh}(\mathrm{ALT})(\mathrm{P} \vee \mathrm{Q}))=\{\{(\mathrm{P} \& \neg \mathrm{Q})\},\{(\mathrm{Q} \& \neg \mathrm{P})\},\{(\mathrm{P} \& \neg \mathrm{Q}), \\
& (\mathrm{Q} \& \neg \mathrm{P})\}\} \\
& \mathrm{EXCL}_{\text {max }}^{\prime}=\{\{(\mathrm{P} \& \neg \mathrm{Q}),(\mathrm{Q} \& \neg \mathrm{P})\}\} \\
& \mathrm{IE}^{\prime}=\cap \mathrm{EXCL}_{\text {max }}^{\prime}=\{(\mathrm{P} \& \neg \mathrm{Q}),(\mathrm{Q} \& \neg \mathrm{P})\}
\end{aligned}
$$

$$
\begin{aligned}
& \operatorname{Exh}\left(\mathrm{ALT}^{\prime}\right)(\operatorname{Exh}(\mathrm{ALT})(\mathrm{P} \vee \mathrm{Q}))= \\
& \underline{(\mathrm{P} \vee \mathrm{Q}) \& \neg(\mathrm{P} \& \neg \mathrm{Q}) \& \neg(\mathrm{Q} \& \neg \mathrm{P})}=\underline{(\mathbf{P} \& \mathbf{Q})}
\end{aligned}
$$


Conjunction and disjunction in a language without 'and'

Conjunction of the prejacent $(\mathrm{P} \vee \mathrm{Q})$ with the negated propositions in $\mathrm{IE}^{\prime}$ yields the final strengthened reading of $P$ manu $Q$ in $(34)$ : $((\mathrm{P} \vee \mathrm{Q}) \& \neg(\mathrm{P} \& \neg \mathrm{Q}) \& \neg(\neg \mathrm{P}$ $\& \mathrm{Q}))=(\mathrm{P} \& \mathrm{Q})$. This conjunctive reading is how Warlpiri speakers use $P$ manu $Q$ in unembedded contexts. For a complete formal discussion of this strengthening process, I refer the reader to the supplementary materials portion of Singh et al. 2013: 49-52.

\section{Pragmatic constraints on Exh application}

In section 3, I presented an account for the strengthening of the Warlpiri disjunctive expression $P$ manu $Q$ to conjunction in unembedded contexts. This account followed Singh et al. (2013) and used the Exh operator posited by Fox (2007). I will now provide an account for the data on $P$ manu $Q$ presented in Table 1, which is outside the scope of Singh et al.'s original paper. ${ }^{8}$

I will also propose some pragmatic constraints on Exh application. In short, I propose that listeners interpret $P$ manu $Q$ constructions as strongly as possible, in the spirit of Gricean conversational maxims. Exhaustification is possible if it results in a reading that is not weaker than the original, non-exhaustified expression. Futhermore, exhaustification is obligatory if Exh application results in the removal of all ignorance inferences regarding $\{\mathrm{P}, \mathrm{Q}\}$. In the context of unembedded and negated utterances, this results in unambiguous interpretations of $P$ manu $Q$. In the context of the antecedents of conditionals and Wh-questions, this results in ambiguity.

\subsection{Exh application in unembedded contexts}

(35)-(36) below summarize the application of Exh to $P$ manu $Q$ in unembedded contexts, in comparison with English $P$ or $Q$ and $P$ and $Q$. The non-exhaustified interpretation of $P$ manu $Q$ is marked with an asterisk, since it is unaccounted for in my fieldwork:

(35) Non-exhaustified constructions:
a. ${ }^{*} P$ manu $Q=\mathrm{P} \vee \mathrm{Q}$
b. $P$ or $Q=\mathrm{P} \vee \mathrm{Q}$
c. $P$ and $Q=\mathrm{P} \& \mathrm{Q}$

8 Singh et al. also discuss constructions which I do not consider here, including childrens' interpretation of disjunction under the scope of universal quantification. 
(36) Exhaustified constructions:

$$
\begin{aligned}
& \text { a. } \operatorname{Exh}(\operatorname{Exh}(P \text { manu } Q))=\mathrm{P} \& \mathrm{Q} \\
& \text { b. } \operatorname{Exh}(P \text { or } Q)=(\mathrm{P} \vee \mathrm{Q}) \& \neg(\mathrm{P} \& \mathrm{Q})
\end{aligned}
$$

Recursive Exh application to $P$ manu $Q$ yields a conjunctive interpretation. This conjunctive reading is stronger than non-exhaustified $P$ manu $Q$, since $(\mathrm{P} \& \mathrm{Q})$ entails $(\mathrm{P} \vee \mathrm{Q})$. Recursive exhaustification of $P$ manu $Q$ additionally results in the removal of all ignorance inferences regarding $\{\mathrm{P}, \mathrm{Q}\}$. I propose that since exhaustification removes all ignorance inferences, Warlpiri listeners must categorically exhaustify unembedded $P$ manu $Q$. This differs from the exhaustification of English $P$ or $Q$, which results in an exclusive 'or' interpretation $((\mathrm{P} \vee \mathrm{Q}) \& \neg(\mathrm{P} \& \mathrm{Q}))$. Since Exh application to $P$ or $Q$ does not remove all ignorance inferences, exhaustification is not obligatory and can be cancelled.

\subsection{Exh application under the scope of negation}

I will begin by assuming that Exh can apply either above negation (globally), or below negation (locally). That is, the following two LFs are possible in principle: ${ }^{9}, 10$

$$
\begin{aligned}
& \text { [Exh [Exh [NEG }[P \text { manu } Q]]]] \\
& \text { [NEG [Exh }[\operatorname{Exh}[P \text { manu } Q]]]]
\end{aligned}
$$$$
\text { (global exhaustification) }
$$

(local exhaustification)

I give the interpretations of non-exhaustified, globally exhaustified, and locally exhaustified $P$ manu $Q, P$ or $Q$, and $P$ and $Q$ in (39)-(41). Under the scope of negation, speakers unambiguously interpret $P$ manu $Q$ as expressing a conjunction of negated propositions:

(39) Non-exhaustified constructions:
a. $\neg(P$ manu $Q)=\neg(\mathrm{P} \vee \mathrm{Q})=\neg \mathrm{P} \& \neg \mathrm{Q}$
b. $\neg(P$ or $Q)=\neg(\mathrm{P} \vee \mathrm{Q})=\neg \mathrm{P} \& \neg \mathrm{Q}$
c. $\neg(P$ and $Q)=\neg(\mathrm{P} \& \mathrm{Q})=\neg \mathrm{P} \vee \neg \mathrm{Q}$

(40) Globally exhaustified constructions:
a. $\operatorname{Exh}(\operatorname{Exh}(\neg(P$ manu $Q)))=\neg(\mathrm{P} \vee \mathrm{Q})=\neg \mathrm{P} \& \neg \mathrm{Q}$
b. $\operatorname{Exh}(\neg(P$ or $Q))=\neg(\mathrm{P} \vee \mathrm{Q})=\neg \mathrm{P} \& \neg \mathrm{Q}$

(41) Locally exhaustified constructions:

9 In the following bracketed structures, I will omit the second argument of Exh (ALT) for simplicity. Assume that Exh still combines with both ALT and the prejacent, as shown previously in section 3 .

10 I assume that negation using kula 'NEG' always outscopes manu. Even if it does not, $(\neg \mathrm{P}$ manu $\neg \mathrm{Q})$ is still strengthened by Exh application to $(\neg \mathrm{P} \& \neg \mathrm{Q})$. 
Conjunction and disjunction in a language without 'and'

$$
\begin{aligned}
& \text { a. } * \neg(\operatorname{Exh}(\operatorname{Exh}(P \operatorname{manu} Q)))=\neg(\mathrm{P} \& \mathrm{Q})=\neg \mathrm{P} \vee \neg \mathrm{Q} \\
& \text { b. }{ }^{*} \neg(\operatorname{Exh}(P \text { or } Q)=\neg((\mathrm{P} \vee \mathrm{Q}) \& \neg(\mathrm{P} \& \mathrm{Q}))
\end{aligned}
$$

When Exh applies locally, the resulting expression is a disjunction of negated propositions (by de Morgan's laws: $\neg(\mathrm{P} \& \mathrm{Q}) \Longleftrightarrow(\neg \mathrm{P} \vee \neg \mathrm{Q})$ ). This expression is weaker than a non-exhaustified or globally exhaustified usage of $P$ manu $Q$ under negation, which is interpreted as a conjunction of negated propositions (again, by de Morgan's laws: $\neg(\mathrm{P} \vee \mathrm{Q}) \Longleftrightarrow(\neg \mathrm{P} \& \neg \mathrm{Q}))$. Since exhaustified $P$ manu $Q$ is weaker than both non-exhaustified and globally exhaustified $P$ manu $Q$ under negation $((\neg \mathrm{P}$ $\& \neg \mathrm{Q}) \Longrightarrow(\neg \mathrm{P} \vee \neg \mathrm{Q}))$, the locally exhaustified construction is ruled out.

Global exhaustification is licit in this context, since negation of both nonexhaustified and globally exhaustified $P$ manu $Q$ yield the same, equally strong interpretation $(\neg \mathrm{P} \& \neg \mathrm{Q})$. However, since Exh application does not change the meaning of $P$ manu $Q$ in this context, global exhaustification here is optional.

\subsection{Exh application in the antecedents of conditionals}

Recall from section 1.2.2 that $P$ manu $Q$ can be interpreted both conjunctively and disjunctively in the antecedents of conditionals. I propose that this results from optional Exh application. That is, the following LFs are available:

[if $[P$ manu $Q][\ldots]]$

(no exhaustification)

$$
\text { [if [Exh [Exh [P manu } Q]]][\ldots]]
$$

(exhaustification)

These yield the following interpretations for $P$ manu $Q, P$ or $Q$, and $P$ and $Q:^{11}$

(44) Non-exhaustified constructions:
a. if $(P$ manu $Q)(\ldots)=$ if $(\mathrm{P} \vee \mathrm{Q})(\ldots)$
b. if $(P$ or $Q)(\ldots)=$ if $(\mathrm{P} \vee \mathrm{Q})(\ldots)$
c. if $(P$ and $Q)(\ldots)=$ if $(\mathrm{P} \& \mathrm{Q})(\ldots)$

(45) Exhaustified constructions:
a. if $(\operatorname{Exh}(\operatorname{Exh}(P$ manu $Q)))(\ldots)=$ if $(\mathrm{P} \& \mathrm{Q})(\ldots)$
b. if $(\operatorname{Exh}(P$ or $Q))(\ldots)=$ if $((\mathrm{P} \vee \mathrm{Q}) \& \neg(\mathrm{P} \& \mathrm{Q}))(\ldots)$

I follow von Fintel (1999) in assuming that the antecedents of conditionals create Strawson-downward entailing (SDE), but crucially not downward entailing (DE), environments. ${ }^{12}$ SDE environments do not enter into entailment relationships

11 Global Exh application is also possible in principle, but it doesn't result in removal of the ignorance inferences regarding $\{\mathrm{P}, \mathrm{Q}\}$.

12 Informally, a proposition Q Strawson-entails $\mathrm{P}$ iff $\mathrm{Q}$ together with the presuppositions of $\mathrm{P}$ entail $\mathrm{P}$. 
like DE environments (e.g., negation) do. Non-exhaustified and exhaustified $P$ manu $Q$ therefore do not enter into an entailment relationship in the antecedents of conditionals. Since neither non-exhaustified nor exhaustified $P$ manu $Q$ entails the other in this context, Exh application is possible. And furthermore, since not all ignorance inferences are removed regarding $\{\mathrm{P}, \mathrm{Q}\}$, Exh application is not obligatory. Since Exh application is therefore possible but not obligatory in this environment, $P$ manu $Q$ can be interpreted either conjunctively or disjunctively in the antecedents of conditionals.

\subsection{Exh application in Wh-questions}

Recall from section 1.2.3 that $P$ manu $Q$ can be interpreted both conjunctively and disjunctively in Wh-questions. As in the antecedents of conditionals, I again propose that this results from optional Exh application.

I assume Guerzoni \& Sharvit's (2013) analysis of Wh-questions. Under Guerzoni \& Sharvit's proposal, the LF of Wh-questions includes covert whether, disjunction, and negation:

'Who owns a carpet?'

[who 2 [2 [whether $\left[\ldots \mathrm{t}_{2} \ldots\right.$ owns a carpet $]$ or [NEG [...t 2 .. owns a carpet $\left.\left.\left.]\right]\right]\right]$

This covert negation causes the second disjunct to be a DE environment, licensing reversal of entailment relationships. In the context of $P$ manu $Q$ and optional Exh application, this yields (at least) the following LFs:

(47) No exhaustification:

$\left[W_{2}\left[2\left[\right.\right.\right.$ whether $\left[\ldots \mathrm{t}_{2} \ldots\right.$ P manu $\left.Q\right]$ or $\left[\mathrm{NEG}\left[\ldots \mathrm{t}_{2} \ldots\right.\right.$ P manu $\left.\left.\left.\left.Q\right]\right]\right]\right]$

(48) Exhaustification:

$\left[W h_{2}\left[2\left[\right.\right.\right.$ whether $\left[\right.$ Exh $\left[\operatorname{Exh}\left[\ldots \mathrm{t}_{2} \ldots P\right.\right.$ manu $\left.\left.\left.Q\right]\right]\right]$ or $\left[\right.$ NEG $\left[\right.$ Exh $\left[\right.$ Exh $\left[\ldots \mathrm{t}_{2} \ldots\right.$ $P$ manu $Q]]]]]]]$

These yield the following interpretations for $P$ manu $Q, P$ or $Q$, and $P$ and $Q$ :

Non-exhaustified constructions:

a. Non-exhaustified manu: ${ }^{13}$

$W h_{2}\left[2\left[\right.\right.$ whether $\left[\left(\ldots t_{2} \ldots P\right.\right.$ manu $\left.Q\right)$ or $\neg\left(\ldots t_{2} \ldots P\right.$ manu $\left.\left.\left.\left.Q\right)\right]\right]\right]=$

$=$ For every $\mathrm{x}$, which of $\{(\ldots \mathrm{x} \ldots(\mathrm{P} \vee \mathrm{Q})), \neg(\ldots \mathrm{x} \ldots(\mathrm{P} \vee \mathrm{Q}))\}$ is true?

b. Non-exhaustified or:

$W h_{2}\left[2\left[\right.\right.$ whether $\left[\left(\ldots t_{2} \ldots P\right.\right.$ or $\left.Q\right)$ or $\neg\left(\ldots t_{2} \ldots P\right.$ or $\left.\left.\left.\left.Q\right)\right]\right]\right]=$

$=$ For every $\mathrm{x}$, which of $\{(\ldots \mathrm{x} \ldots(\mathrm{P} \vee \mathrm{Q})), \neg(\ldots \mathrm{x} \ldots(\mathrm{P} \vee \mathrm{Q}))\}$ is true?

13 Note that this predicts that a Wh-question including non-exhaustified $P$ manu $Q$ can be answered positively if both $\mathrm{P}$ and $\mathrm{Q}$ are true. Future elicitation is needed to ensure that this is a possibility. 
Conjunction and disjunction in a language without 'and'

c. Non-exhaustified and:

$W h_{2}\left[2\left[\right.\right.$ whether $\left[\left(\ldots t_{2} \ldots P\right.\right.$ and $\left.Q\right)$ or $\neg\left(\ldots t_{2} \ldots P\right.$ and $\left.\left.\left.\left.Q\right)\right]\right]\right]=$

$=$ For every $\mathrm{x}$, which of $\{(\ldots \mathrm{x} \ldots(\mathrm{P} \& \mathrm{Q})), \neg(\ldots \mathrm{x} . . .(\mathrm{P} \& \mathrm{Q}))\}$ is true?

(50) Exhaustified constructions:

a. Exhaustified manu:

$W h_{2}\left[2\left[\right.\right.$ whether $\left[\left(\operatorname{Exh}\left(\operatorname{Exh}\left(\ldots t_{2} \ldots P\right.\right.\right.\right.$ manu $\left.\left.\left.Q\right)\right)\right)$ or $\neg\left(\operatorname{Exh}\left(\operatorname{Exh}\left(\ldots t_{2} \ldots P\right.\right.\right.$ manu $Q)))]]]=$

$=$ For every $\mathrm{x}$, which of $\{(\ldots \mathrm{x} \ldots(\mathrm{P} \& \mathrm{Q})), \neg(\ldots \mathrm{x} \ldots(\mathrm{P} \& \mathrm{Q}))\}$ is true?

b. Exhaustified or: ${ }^{14}$

$W h_{2}\left[2\left[\right.\right.$ whether $\left[\left(\operatorname{Exh}\left(\ldots t_{2} \ldots P\right.\right.\right.$ or $\left.\left.Q\right)\right)$ or $\left(\operatorname{Exh}\left(\neg\left(\ldots t_{2} \ldots P\right.\right.\right.$ and $\left.\left.\left.\left.\left.\left.Q\right)\right)\right)\right]\right]\right]=$

$=$ For every $\mathrm{x}$, which of $\{(\ldots \mathrm{x} \ldots(\mathrm{P} \vee \mathrm{Q}) \& \neg(\mathrm{P} \& \mathrm{Q})), \neg(\ldots \mathrm{x} \ldots \mathrm{P} \vee \mathrm{Q})\}$ is true?

Wh-questions, like conditional constructions, are not DE (Guerzoni \& Sharvit 2007). (51) below shows this:

(51) Who owns a carpet? $\not \Longrightarrow$ Who owns a flying carpet?

Since there is no entailment relationship between Wh-questions, neither nonexhaustified nor exhaustified $P$ manu $Q$ is stronger than the other in this context. As a result, Exh application is possible in this environment. Futhermore, since not all ignorance inferences are removed regarding $\{\mathrm{P}, \mathrm{Q}\}, E x h$ application is not obligatory.

Since Exh application in Wh-questions is possible but not obligatory, this again results in an ambiguity between a conjunctive and disjunctive interpretation of $P$ manu $Q$. This furthermore predicts that $P$ manu $Q$ should also be ambiguous in polar questions, which also do not enter into entailment relationships. This observation is tentatively upheld by Warlpiri data.

\section{An alternate proposal: manu has a conjunctive denotation and scopes above negation}

An alternate proposal for the interpretation of $P$ manu $Q$ involves altering both the denotation and the scope taking ability of manu. Under this proposal, manu has a conjunctive denotation akin to English and. Assuming that manu has a conjunctive denotation easily accounts for its distribution in basic unembedded coordination constructions. If we furthermore assume that manu denotes a plurality (as in e.g., Link 1983), and also that it can take scope above negation, we can also account for

14 In principle, there are more exhaustification options available (e.g., local exhaustification of $P$ or $Q)$. The availability of multiple exhaustification options is a general feature of theories involving exhaustification. It is beyond the scope of this paper to investigate them all. 
its interpretation in negated constructions. A distributivity operator would distribute the property denoted by the negated predicate over the atomic parts of $P$ manu $Q$, represented in the tree below as $(\mathrm{P} \oplus \mathrm{Q})$ :

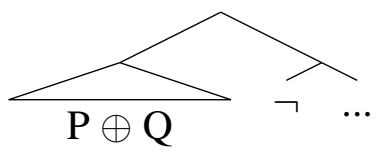

In the following sections, I will outline some of the obstacles for this proposal, and show that an analysis in which manu has a conjunctive denotation and scopes above negation is not feasible.

\subsection{Scopal ambiguities and manu as a PPI}

Movement at LF has been proposed for other scope-taking elements, including quantifiers. These scope-taking elements can be interpreted either at their base-generated position or at their covertly moved scopal position, resulting in an ambiguity:

(52) A gorilla loves every zookeeper.

a. $\exists>\forall$ : There is one gorilla such that that gorilla loves every zookeeper.

b. $\forall>\exists$ : Every zookeeper is such that some gorilla loves them.

If manu underwent covert movement to a position superior to negation at LF, we predict that it should also be able to be interpreted in situ analogously to the surface and inverse scope readings in (52). Ambiguity is observed in some constructions involving (covert) negation, such as Wh-questions. However, there is no ambiguity with respect to manu and overt negation, in which speakers categorically reject a conjunctive interpretation of manu under negation: * $(\neg \mathrm{P} \vee \neg \mathrm{Q})$.

A possible counterargument could assert that manu is a PPI, and therefore cannot occur under the scope of clausemate negation at all. This would prevent the unattested in situ scope interpretation ( $\neg \mathrm{P} \vee \neg \mathrm{Q}$ ) from arising. The proposal that conjunction has PPI-like properties and therefore scopes above negation has also been made for other languages, including Hungarian, Japanese, and Russian (Szabolsci \& Haddican 2004). However, this analysis can not account for the interpretation of manu in questions. For instance, the response in (53) below is a felicitous answer to the given question: 
Conjunction and disjunction in a language without 'and'
A: Cecilia manu Gloria yanu-rnu?
A: Cecilia manu Gloria go.PST-DIREC
A: 'Did Cecilia manu Gloria leave?'
B: Yes, but I don't know which.

If manu has an underlying conjunctive denotation (and we also assume that scoping out of questions is available), then the following interpretations of the question in (54) are predicted:

Did Cecilia тапи Gloria leave?

a. Manu takes wide scope:

Which of $\{\mathrm{P}, \neg \mathrm{P}\}$ and which of $\{\mathrm{Q}, \neg \mathrm{Q}\}$ is true?

b. Manu takes narrow scope:

Which of $\{(\mathrm{P} \& \mathrm{Q}), \neg(\mathrm{P} \& \mathrm{Q})\}$ is true?

While Yes, but I don't know which is a felicitous answer to the question in (54), No, but I don't know which is not. The ambiguity in (54) does not account for this straightforwardly; a positive answer to (54b) does not allow ignorance, and no answer to either of the questions in (54a) allows ignorance. However, the data in (53) is accounted for if we assume an underlyingly disjunctive denotation for manu.

\subsection{Scope islands in Warlpiri}

Various syntactic constructions are argued to contain islands out of which movement is not possible. In English, these include the antecedents of conditionals. Covert movement of quantifiers out of the antecedents of conditionals is not available:

(55) If everyone comes to the party, we'll have a ball.

a. if $>\forall$ : If every person comes to the party, we'll have a ball.

b. $* \forall>$ if: Every person is such that if they come to the party, we'll have a ball; that is, if Bill comes to the party we'll have a ball, if Susan comes to the party we'll have a ball, and so on.

The same island property holds of Warlpiri conditional constructions. In a Warlpiri conditional construction, the universal D-quantifier jintakumarrarni 'all' cannot scope out of the antecedent clause:

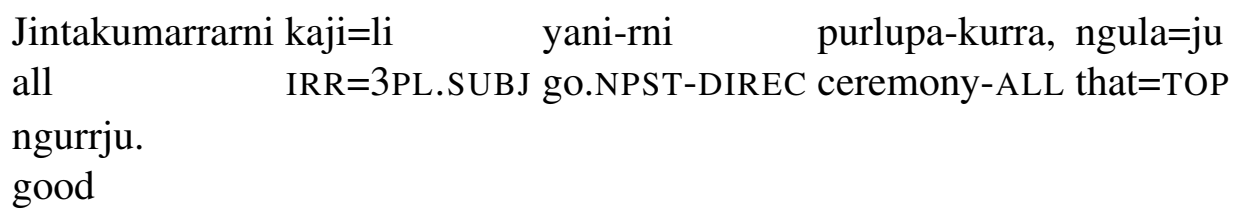


a. if $>\forall$ : If every person comes to the ceremony, it will be good.

b. $* \forall>$ if: $*$ Every person is such that if they come to the ceremony, it will be good; that is, if Nangala comes to the ceremony it will be good, if Napangardi comes to the ceremony it will be good, and so on.

Since the antecedents of Warlpiri conditionals appear to be scope islands, as in English, this suggests that manu does not scope out of the antecedent clause when it is interpreted. Futhermore, as shown in section 1.2.2, manu can occur with a disjunctive interpretation in this environment. Following von Fintel (1999), the SDE properties of the antecedents of conditionals license this reading of manu if we assume an underlying disjunctive denotation.

\section{Conclusion}

This paper proposed a pragmatic analysis for the Warlpiri coordination construction $P$ manu $Q$. I proposed that the Warlpiri coordinator manu has an unstrengthened disjunctive denotation which can undergo pragmatic strengthening to conjunction. This strengthening process utilizes Fox's (2007) syntactic exhaustivity operator Exh; recursive application of Exh to the Warlpiri alternatives for disjunction yields conjunction.

I extended the scope of Singh et al.'s (2013) recursive exhaustification proposal for childrens' English to include the interpretation of recursively exhaustified disjunction in embedded contexts, including the antecedents of conditionals and in Wh-questions. I showed that if Warlpiri listeners' application of Exh is motivated by obtaining the strongest possible reading of an utterance, and if exhaustification is obligatory when it results in the removal of all ignorance inferences regarding $\{P$, Q\}, the ambiguity between conjunction and disjunction observed in these embedded environments is predicted. This also accounts for manu's categorical conjunctive reading in unembedded contexts, and categorical disjunctive reading under negation.

This proposal also makes predictions about the interpretation of $P$ manu $Q$ in upward-entailing (UE) contexts, including under UE, factive verbs like know. These verbs create an environment in which $P$ manu $Q$ should be obligatorily strengthened to conjunction-falling out from the fact that know $(P \& Q)$ is stronger than know $(P \vee Q)$. This prediction is tentatively supported by my fieldnotes, which show that a conjunctive reading of $P$ manu $Q$ is available under milya-pinyi 'know.' Further fieldwork will include the interpretation of $P$ тапи $Q$ in alternative and polar disjunctive questions, and under the scope of universal quantification and deontic necessity modality. 
Conjunction and disjunction in a language without 'and'

\section{References}

Fox, Danny. 2007. Free choice disjunction and the theory of scalar implicature. In Uli Sauerland \& Penka Stateva (ed.), Presupposition and Implicature in Compositional Semantics, 71-120. Palgrave Macmillan.

Fox, Danny \& Roni Katzir. 2011. On the characterization of alternatives. Natural Language Semantics 19(1). 87-107.

Grice, H. Paul. 1975. Logic and conversation. In Peter Cole \& Jerry Morgan (ed.), Speech Acts, 41-58. Academic Press.

Guerzoni, Elena \& Yael Sharvit. 2007. A question of strength: on NPIs in interrogative clauses. Linguistics and Philosophy 30. 361-391.

Guerzoni, Elena \& Yael Sharvit. 2013. Whether or anything but not whether anything or not. USC \& UCLA, ms.

Katzir, Roni. 2008. Structurally-defined alternatives. Linguistics and Philosophy 30. 669-690.

Link, Godehard. 1983. The logical analysis of plurals and mass terms: a latticetheoretical approach. In Rainer Bäuerle, Christoph Schwarze, \& Arnim von Stechow (eds.), Meaning, Use, and Interpretation of Language, 302-323. De Gruyter.

Meyer, Marie-Christine. 2012. Generalized free choice and missing alternatives. MIT, ms.

Sauerland, Uli. 2004. Scalar implicatures in complex sentences. Linguistics and Philosophy 27. 367-391.

Singh, Raj, Ken Wexler, Andrea Astle, Deepthi Kamawar, \& Danny Fox. 2013. Children interpret disjunction as conjunction: consequences for the theory of scalar implicature. Carleton University, ms.

Szabolsci, Anna \& Bill Haddican. 2004. Conjunction meets negation. Journal of Semantics 21. 219-249.

von Fintel, Kai. 1999. NPI-licensing, Strawson-entailment, and context-dependency. Journal of Semantics 16(1). 97-148.

Zimmermann, Thomas Ede. 2001. Free choice disjunction and epistemic possibility. Natural Language Semantics 8. 255-290.

Margit Bowler

UCLA Department of Linguistics

3125 Campbell Hall

Los Angeles, CA 90095-1543

margitbowler@gmail.com 